\title{
Uric acid and the cardio-renal effects of SGLT2 inhibitors
}

Clifford J Bailey

Correspondence to:

Clifford J. Bailey,

School of Life and Health Sciences,

Aston University,

Birmingham B4 7ET, UK

c.j.bailey@aston.ac.uk

Tel +44 1212043898

Fax +44 1212044187

Running title.

Uric acid and SGLT2 inhibitors

1 Figure,

No tables

ABSTRACT

Sodium/glucose co-transporter-2 (SGLT2) inhibitors, which lower blood glucose by increasing renal glucose elimination have been shown to reduce the risk of adverse cardiovascular (CV) and renal

This article has been accepted for publication and undergone full peer review but has not been through the copyediting, typesetting, pagination and proofreading process, which may lead to differences between this version and the Version of Record. Please cite this article as doi: 10.1111/dom.13670

This article is protected by copyright. All rights reserved. 
events in type 2 diabetes. This has been ascribed in part to haemodynamic changes, body weight reduction and several possible effects on myocardial, endothelial and tubulo-glomerular functions as well as reduced glucotoxicity. This review evaluates evidence that an effect of SGLT2 inhibitors to lower uric acid may also contribute to reduced cardio-renal risk.

Chronically raised circulating uric acid concentrations are associated with increased risk of hypertension, CV disease and chronic kidney disease (CKD). The extent to which uric acid contributes to these conditions either as a cause or aggravating factor remains unclear, but interventions that reduce urate production or increase urate excretion in hyperuricaemic patients have consistently improved cardio-renal prognoses. Uric acid concentrations are often raised in type 2 diabetes, contributing to the 'metabolic syndrome' of CV risk. Treating type 2 diabetes with an SGLT2 inhibitor increases uric acid excretion, reduces circulating uric acid and improves parameters of $\mathrm{CV}$ and renal function. This raises the possibility that the lowering of uric acid by SGLT2 inhibition may assist in reducing adverse CV events and slowing progression of CKD in type 2 diabetes. SGLT2 inhibition might also be useful in the treatment of gout and gouty arthritis, especially when coexistent with diabetes.

\section{Introduction}

Sodium/glucose co-transporter-2 (SGLT2) inhibitors lower blood glucose in an insulin-independent manner by reducing the reclamation of glucose from the renal filtrate [ 1 ]. The resulting glucosuria causes caloric loss which assists weight control and generates an osmotic diuresis that may contribute to a lowering of blood pressure [2]. Studies in type 2 diabetes indicate that treatment with an SGLT2 inhibitor can reduce the risk of some major adverse cardiovascular events (MACE) and slow or reverse aspects of deteriorating renal function: and these effects are at least partly independent of glucose-lowering efficacy [ 3 ]. How SGLT2 inhibitors exert these cardiovascular (CV) and renal effects is not entirely clear, and several potential mechanisms have been proposed. One possible contributing factor may be a reduction in the circulating concentration of uric acid. This review considers how SGLT2 inhibitors affect uric acid, and the implications for CV and renal function in type 2 diabetes and in hyperuricaemia.

\section{Cardio-renal effects of SGLT2 inhibitors}

Several recent large prospective randomised studies in type 2 diabetes have observed reduced CV risk and improved renal function during treatment with an SGLT2 inhibitor [3]. In the EMPA-REG OUTCOME trial treatment with empagliflozin was associated with a reduced composite 3-point MACE of CV death, nonfatal myocardial infarction (MI) and stroke by $14 \%$ : CV mortality was reduced by $38 \%$, overall mortality by $32 \%$ and hospitalisation for heart failure by $35 \%$ [ 4 ]. Empagliflozin also reduced by $39 \%$ the deterioration in nephropathy (measured as a composite of progression to macroalbuminuria, doubling of serum creatinine, initiation of renal-replacement therapy or death from renal disease) [5].

In the CANVAS Program, canagliflozin also reduced the 3-point MACE of CV death, nonfatal MI and stroke by $14 \%$, but did not significantly alter CV deaths or overall mortality, although hospitalisation for heart failure was reduced by $33 \%$. Canagliflozin also reduced (by $40 \%$ ) a composite of decreased glomerular filtration rate, need for renal replacement therapy or death from renal causes, alongside a nominal $27 \%$ reduction in the progression of albuminuria [6 ]. In the DECLARE trial, dapagliflozin reduced hospitalisation for heart failure by $27 \%$ and reduced a renal composite of decreased glomerular filtration rate, end stage renal disease or death from renal or CV causes by 24\% [7]

This article is protected by copyright. All rights reserved. 
Several large database studies have noted reductions in CV deaths and hospitalisation for heart failure amongst type 2 diabetes patients treated with an SGLT2 inhibitor [ 8] and there is emerging evidence that the occurrence of acute kidney injury is reduced [9].

While reduced glucotoxicity may contribute to the cardio-renal benefits of SGLT2 inhibitors, the correlation with glucose-lowering is modest [3, 10-12]. The CV effects emerge too quickly to be explained by decreased body weight, improved insulin sensitivity or reduced atherosclerosis [13]. Haemodynamic effects consequent to the osmotic diuresis, such as lowered blood pressure and decreased intra-vascular volume are anticipated to play a role in the CV and renal effects [14], and increased delivery of sodium to the macular densa during SGLT2 inhibition will increase the release of adenosine which mediates tubulo-glomerular feedback to constrict afferent glomerular vessels and protect glomeruli through reduced intra-glomerular pressure $[15,16]$.

There are several possible mechanisms through which SGLT2 inhibition could assist myocardial function in ischaemia. Lowering blood glucose together with reduced insulin concentrations will promote lipolysis and increase diversion of fatty acids into ketones: availability of ketones will provide a rapidly usable energy source to facilitate contraction by cardiac muscle $[17,18]$. Decreased catabolism of branched-chain amino acids (BCAAs) in heart failure disrupts myocardial pyruvate utilization and increases susceptibility to ischaemia-reperfusion injury. Improved myocardial metabolism with use of an SGLT2 inhibitor can partially overcome this effect $[19,20]$. SGLT2 inhibition has also been shown to reduce activity of the sarcolemmal $\mathrm{Na}^{+} / \mathrm{H}^{+}$exchanger in the myocardium, which favours a lowering of intracellular sodium and a rise in mitochondrial calcium [21]. Another potential inotropic influence of SGLT2 inhibition might involve the small increase in plasma glucagon observed with use of an SGLT2 inhibitor [22].

A further potential mechanism through which SGLT2 inhibitors might influence CV risk is via a reduction in the circulating concentration of uric acid, considered below.

\section{SGLT2 inhibitors and uric acid}

Uric acid is mostly produced from the breakdown of dietary and endogenous purines, and about two thirds of uric acid is excreted in the urine. At near neutral physiological $\mathrm{pH}$, uric acid exists almost entirely as the urate anion, but in high concentration at low $\mathrm{pH}$ uric acid is prone to form the characteristic crystals of nephrolithiasis and gout $[23,24]$. Raised serum uric acid concentrations are associated with increased CV risk, and are recognised as part of the collection of CV risk factors that typically accompanies insulin resistance [25-27]. Raised uric acid concentrations are also associated with renal tubulo-interstitial fibrosis and chronic kidney disease (CKD) [28-30]. Many different pathways of increased production and/or reduced elimination of uric acid can account for raised serum uric acid as reviewed elsewhere $[23,24]$, but it is relevant to note in the context of type 2 diabetes that uric acid production is increased by a diet high in fructose (corn syrup). This is because excess uncontrolled phosphorylation of fructose by fructokinase in the liver depletes ATP to ADP and AMP and the adenosine is converted to uric acid [23]. High uric acid concentrations promote insulin resistance by inhibition of postreceptor insulin signalling pathways [ 31, 32 ].

Uric acid concentrations are generally higher in type 2 diabetes patients than in non-diabetic individuals, and although uric acid concentrations are usually still within the normal physiological range, they are independently associated with an additional risk of CV and renal disease [33-35]. Although type 2 diabetes is associated with an increased risk of gout this appears to be mostly attributable to the co-morbidities linked to the diabetes [36].

This article is protected by copyright. All rights reserved. 
In a meta-analysis of 62 clinical trials with a total of 34,941 type 2 diabetes patients, treatment with an SGLT2 inhibitor consistently reduced circulating uric acid concentrations [37]. When baseline uric acid values were within a normal range [eg 200-400 umol/L ( 3.3-6.7 mg/dL)], SGLT2 inhibitors available in Europe and North America (canagliflozin, dapagliflozin and empagliflozin) usually reduced serum/plasma uric acid concentrations by $35-45 \mathrm{umol} / \mathrm{L}(0.60-0.75 \mathrm{mg} / \mathrm{dL})$ in trials of 6-12 months. The effect was rapidly generated (within days) and persisted throughout trials of 2 years duration [37]. Reductions of uric acid are generally greater if the HbA1c value is higher, consistent with greater uricosuria accompanying greater glucosuria (discussed below), but there was no clear difference in the extent of uric acid-lowering across the range of 'low-to-high' normal uric acid values. At therapeutic doses of SGLT2 inhibitors, mean reductions in plasma/serum uric acid with use of empagliflozin ( $45 \mathrm{umol} / \mathrm{L}$ at $10 \mathrm{mg}$ and $25 \mathrm{mg}$ ) were typically marginally (not significantly) greater than with canagliflozin ( $\sim 2 \mathrm{umol} / \mathrm{L}$ at $100 \mathrm{mg}$ and $300 \mathrm{mg}$ ) and dapagliflozin ( $38 \mathrm{umol} / \mathrm{L}$ at $10 \mathrm{mg}$ ), but there were no consistent dose-related effects or correlations with differences in the IC50 values for inhibition of the SGLT transporters [37]. More detailed comparisons between agents are limited by many confounding variables and incomplete information, such as uncertainties regarding the history or presence of CV disease and kidney disease, and the use of potentially interfering medications. Thus the similar lowering of uric acid observed with each of the SGLT2 inhibitors indicates a class effect with no substantive differences between agents or doses used routinely in the treatment of type 2 diabetes.

The uric acid-lowering effect of SGLT2 inhibitors raises questions regarding the mechanism, whether the effect is relevant to the reduced cardio-renal risk associated with SGLT2 inhibitors, and whether there are implications for the treatment of hyperuricaemia?

\section{Renal handling of uric acid with SGLT2 inhibitors}

SGLT2 inhibitors lower urate concentrations by increasing renal urate elimination [38, 39]. Urate is freely filtered by the kidney and also reabsorbed and secreted along the proximal convoluted tubule (PCT) [40]. Almost all of the filtered urate is reabsorbed in the first segment (S1) of the PCT: uptake across the apical membrane is mostly via the urate transporter URAT1 (SLC22A12) and the facilitative hexose/urate transporter GLUT9b (SLC2A9 isoform b) with minor contributions of the organic anion transporters OAT4 and OAT10. Transfer of urate out of the proximal cells across the basolateral membrane is via GLUT9a (SLC2A9 isoform a) (Fig 1). The near total reuptake of filtered urate indicates that tubular secretion must be important for the overall elimination of urate. Secretion is mostly in the second segment (S2) of the PCT and more distal regions of the nephron where urate is transferred from the interstitium across the basolateral membrane via OAT1 and OAT3. The uric acid is then transferred across the apical membrane into the lumen of the nephron mostly via multidrug resistance-associated protein-4 (MRP4) and ATP-binding cassette transporter G2 (ABCG2). The sodium/phosphate cotransporters NPT1 and NPT4 may also transport urate across the apical membrane into the lumen [40-44].

URAT1 is inhibited by uricosuric agents that lower serum urate such as probenecid, losartan and lesinurad [45]. Also, mutations that reduce the function of URAT1 increase uricosuria and reduce serum urate [46], and URAT1 knockout mice show increased uricosuria [42]. However SGLT2 inhibitors do not appear to affect URAT1 [38]. The more likely mechanism through which SGLT2 inhibitors increase uricosuria and lower circulating uric acid is by suppression of the activity of GLUT9b. When the transport function of SGLT2 is reduced there is an increased concentration of glucose within the lumen of the PCT which competes with urate for GLUT9b [39]. Indeed, the reduction in serum urate in type 2 diabetes patients receiving an SGLT2 inhibitor declines at low eGFR ( $\left.<60 \mathrm{~mL} / \mathrm{min} / 1.73 \mathrm{~m}^{2}\right)$ as does the glucosuria, consistent with reduced filtration of both urate

This article is protected by copyright. All rights reserved. 
and glucose, and thence reduced competition for the hexose/urate transporter [37]. Also, uricosuria was increased and plasma uric acid was reduced in a study of type 1 diabetes patients in whom euglycaemia was clamped while glucosuria was induced with an SGLT2 inhibitor [39].

\section{Uric acid, hypertension and adverse CV events}

A persistently raised uric acid concentration has been implicated as a risk factor for hypertension and for several types of MACE.

\section{Hypertension}

Many epidemiological analyses have concluded that hyperuricaemia is an independent risk factor for hypertension [47-50]. The association of raised uric acid and raised blood pressure is evident within the normal range of uric acid concentrations, and interventions that lower uric acid concentrations (such as the xanthine oxidase inhibitors allopurinol and febuxostat which reduce uric acid production) modestly reduce blood pressure in hypertensive patients independently of antihypertensive therapies [51-55]. This suggests a possible pathogenic role of raised uric acid in the development of raised blood pressure. Elevated uric acid concentrations have been reported to alter several parameters of vascular function indicative of arterial stiffness, notably higher carotidfemoral and carotid-radial pulse wave velocities and impaired flow-mediated vasodilation [56-57]. Hyperuricaemic hypertension is also typically associated with increased activity of the reninangiotensin-aldosterone system (RAAS) including increased plasma renin activity and increased aldosterone secretion, and hyperuricaemia has been linked with increased salt-sensitivity in some individuals [58-62]. However, the extent to which excess uric acid might contribute to these effects is unclear [63].

\section{Major adverse cardiovascular events}

Observational and cohort studies have noted an association of hyperuricaemia with CV death, nonfatal MI and stroke, atrial fibrillation and heart failure [64-69], and modestly raised uric acid concentrations within the normal concentration range represent a risk for adverse CV events [7073]. For example, a meta-analysis of 29 prospective cohort studies totalling 958,410 participants found a $13 \%$ increased relative risk of CV mortality for each $1 \mathrm{mg} / \mathrm{dL}(59.5 \mathrm{umol} / \mathrm{L})$ increase in uric acid [73]. Indeed, raised uric acid may be associated with a greater increase in CV mortality in people with type 2 diabetes than the general population [74]. Assessing whether uric acid is an independent risk factor for $\mathrm{CV}$ events is confounded by the co-existence of other $\mathrm{CV}$ risk factors [7577]. A meta-analysis of 11 studies with 172,123 participants indicated uric acid was an independent predictor of CV mortality [78], whereas another meta-analysis involving 16 studies and 164,342 participants was inconclusive [79].

Lowering uric acid concentrations with xanthine oxidase inhibitors (allopurinol or febuxostat) or a uricosuric agent (probenecid) reduces $\mathrm{CV}$ events and improves the $\mathrm{CV}$ prognosis of patients with gout. Many prospective and observational studies have confirmed reduced risk of fatal and nonfatal stroke and $\mathrm{MI}$ amongst patients receiving allopurinol and this has been linked to reduced uric acid concentrations, although it is recognised that allopurinol exerts relevant anti-oxidant effects independently of uric acid [80-85]. In a propensity score-matched cohort study there was an $11 \%$ reduction in a composite outcome of $\mathrm{MI}$, stroke and $\mathrm{CV}$ death and a $32 \%$ reduction in all-cause mortality amongst 7,127 patients receiving allopurinol [86]. A case-control analysis of a cohort of 25,090 patients with heart failure found that use of allopurinol for those with gout was associated

This article is protected by copyright. All rights reserved. 
with a $31 \%$ reduction of heart failure readmission or death, and a $26 \%$ reduction of all-cause mortality [87]. Prospective studies with febuxostat and probenecid have also reduced adverse CV events together with reduced uric acid concentrations in patients with gout. This suggests that the anti-oxidant effects of allopurinol are unlikely to fully explain the improved CV prognosis with this agent, supporting the possibility that reduced uric acid itself contributes to improved $\mathrm{CV}$ prognosis [88-90].

Several mechanisms could account for the epidemiological link between hyperuricaemia and CV risk. Although circulating uric acid has potentially beneficial antioxidant properties, intracellular uric acid stimulates nicotinamide adenine dinucleotide phosphate (NADPH) oxidases which generate reactive oxygen species (ROS) [91-93]. ROS cause endoplasmic stress which in turn accentuates ROS production by mitochondria and interfere with several key cellular signalling pathways. Increased uric acid promotes pro-inflammatory responses and fibrosis within the vascular wall and increases turnover of vascular smooth muscle [94-99]. Hyperuricaemia is also associated with an increased rate of apoptosis of endothelial cells [100] and depleted nitric oxide (NO) levels due to reduced NO production and to increased conversion of NO to 6 -aminouracil [101, 102].

\section{Uric acid and CKD}

Mounting evidence implicates chronic hyperuricaemia as a risk for development and progression of CKD, especially in diabetes. A 5-year prospective study of 1,449 type 2 diabetes patients with normal kidney function found the incidence of CKD (eGFR $<60 \mathrm{~mL} / \mathrm{min} / 1.73 \mathrm{~m}^{2}$ ) more than doubled (29\% versus $11 \%$ ) with raised uric acid concentrations $(>7.0$ or $6.5 \mathrm{mg} / \mathrm{dL}$ for men or women respectively, or allopurinol treatment) after adjusting for other variables [103]. A 4-year cohort study of 13,964 type 2 diabetes patients noted that raised uric acid concentrations are strongly associated with increased risk of CKD [104], and faster progression of CKD was independently linked to higher uric acid concentrations in a 4.6 year cohort study of 2,367 type 2 diabetes patients [105]. A raised uric acid:creatinine ratio predicted development of CKD in a 4 year study of 1,339 type 2 diabetes patients [106], and raised uric acid concentrations independently predicted the rate of progression of CKD in a retrospective analysis of 270 type 2 diabetes patients with CKD [107]. An independent association of raised uric acid concentrations with the development and progression of CKD has been noted in prospective and retrospective studies with non-diabetic populations and in prospective studies with type 1 diabetes patients [108-111].

Several studies have implicated uric acid as a modifiable risk factor for progression of CKD in type 2 diabetes. A post-hoc analysis of 1,342 type 2 diabetes patients with nephropathy in the RENAAL (Reduction of End Points in Non-Insulin-Dependent Diabetes Mellitus With the Angiotensin II Antagonist Losartan) trial found a $6 \%$ decrease in adverse renal outcomes for each $0.5 \mathrm{mg} / \mathrm{dL}$ (30 umol/L) decrease in uric acid concentrations during 6 months of treatment with losartan (URAT1 inhibitor) [112]. Interventions to reduce uric acid concentrations reduced CKD progression in individuals with and without type 2 diabetes [105, 113], and lowering uric acid with allopurinol in diabetic $(d b / d b)$ mice reduced albuminuria and ameliorated tubule-interstitial injury, but did not prevent mesangial expansion [114].

Although urate crystal formation in the renal tubules and interstitium contributes to kidney damage in individuals with severe hyperuricaemia, other mechanisms are undoubtedly important, particularly in people with lesser degrees of hyperuricaemia $[115,116]$. Hypertension, afferent glomerular hypertension and afferent vessel thickening associated with raised uric acid concentrations in animal studies are anticipated to contribute to glomerular disease in humans [117, 118]. Activation of NADPH oxidases, generation of ROS and endoplasmic stress have also been

This article is protected by copyright. All rights reserved. 
linked to increased production of extracellular matrix, inflammation and interstitial fibrosis with reduced tubular cell viability $[119,120]$ : uric acid decreased viability and increased apoptosis of cultured human proximal tubule (HK-2) cells, and this was prevented by inhibition of NADPH oxidases and inhibition of urate transport into the cells [96]. Epithelial-to-mesenchymal transition (EMT) was increased by uric acid in cultured rat tubular (NRK) cells, and the interstitial fibrosis in rats with experimental hyperuricaemia was reduced by allopurinol [121]. Raised uric acid concentrations promote inflammatory responses of renal tubular cells by increasing production of nuclear factor-KB (NF-kB), tumour necrosis factor-alpha (TNF $\alpha$ ), monocyte chemoattractant protein1 (MCP-1) and 'regulated upon activation normal T-cell expressed and presumably secreted' (RANTES) proten [122]. The inflammatory effect of raised uric acid concentrations in mice is associated with increased infiltration of T-cells and macrophages in the renal interstitial spaces, and this is relieved by the uricosuric probenecid [122]. In cultured glomerular mesangial cells endoplasmic stress induced by raised uric acid increased production of biomarkers of fibrogenesis such as $\alpha$-smooth muscle actin ( $\alpha$-SMA), transforming growth factor- $\beta 1$ (TGF- $\beta 1$ ) and fibronectin [123].

Thus accumulating evidence suggests that raised uric acid concentrations have a detrimental effect on glomerular and tubule-interstitial integrity independently of hypertension, and these effects are ameliorated by therapies that lower uric acid concentrations.

\section{Treatment of gout}

The increased uric acid elimination with use of SGLT2 inhibitors usually lowers circulating uric acid concentrations by about $35-45 \mathrm{umol} / \mathrm{L}(0.60-0.75 \mathrm{mg} / \mathrm{dL})$ in individuals with a baseline uric acid value in the normal concentration range of $\sim 200-400 \mathrm{umol} / \mathrm{L}(\sim 3.3-6.7 \mathrm{mg} / \mathrm{dL})$. Comparing the uric acid-lowering efficacy of SGLT2 inhibitors with that of allopurinol or febuxostat is not straightforward as the latter agents are mostly used in gouty patients with much higher baseline uric acid concentrations than in studies with SGLT2 inhibitors, and doses of the xanthine oxidase inhibitors are customarily titrated aiming to reduce uric acid values to $<6 \mathrm{mg} / \mathrm{dL}$ ( $<360 \mathrm{umol} / \mathrm{L}$ ) [124127]. In hyperuricaemic patients, up-titration of allopurinol and febuxostat achieves reductions of serum/plasma uric acid concentrations by 30-40\% [ 1-4 mg/dL (60-240 umol/L)] from a typical baseline of 8-12 mg/dL ( $\sim 475-710 \mathrm{umol} / \mathrm{L}$ ). Where modest doses of allopurinol have been used in individuals with uric acid concentrations at the upper end of the normal serum/plasma range, reductions of circulating uric acid are more commonly around $1-1.5 \mathrm{mg} / \mathrm{dL}(60-90 \mathrm{umol} / \mathrm{L})$.

Although SGLT2 inhibitors lower uric acid concentrations [typically 0.60-0.75 mg/dL (35-45 umol/L)] within the normal range with lesser potency than xanthine oxidase inhibitors, their mode of action is different and potentially complementary, offering the possibility of an additive effect if used with a xanthine oxidase inhibitor. The renal mechanism of action of SGLT2 inhibitors to increase uric acid elimination is also different to the URAT1 inhibiting uricosuric agents such as probenecid, suggesting potential for additive efficacy. Whether SGLT2 inhibitors might be useful in the management of hyperuricaemia is now being investigated, for example in a small $(n=36)$ randomised clinical study comparing dapagliflozin and febuxostat over 7 days in hyperuricaemic patients [128]. There are also examples of derivatives of current SGLT2 inhibitors that are particularly potent uricosuric agents, such as 3-oxy dapagliflozin [129]. It is appreciated that increased uric acid elimination in the urine with use of an SGLT2 inhibitor could aggravate the risk of renal calculi, but studies to date have not observed this possible long-term risk [130].

This article is protected by copyright. All rights reserved. 


\section{Conclusions}

Raised uric acid concentrations are associated with increased adverse cardiovascular and renal events in diabetic and non-diabetic individuals. Although there are isolated reports that metformin and pioglitazone reduced symptoms in some patients with gout, there is no consistent evidence that glucose-lowering agents can reduce uric acid concentrations in type 2 diabetes, except for SGLT2 inhibitors [131-133]. The uric acid-lowering effect of SGLT2 inhibitors may contribute to the cardiorenal benefits associated with this class of glucose-lowering agent (Fig 2), and it is possible that SGLT2 inhibitors may assist the management of hyperuricaemia in diabetes.

\section{REFERENCES}

1. Tahrani AA, Barnett AH, Bailey CJ. SGLT inhibitors in management of diabetes. Lancet Diabetes Endocrinol 2013, 1, 140-51.

2. Mudaliar S, Polidori D, Zambrowicz B, Henry RR. Sodium-glucose cotransporter inhibitors: effects on renal and intestinal glucose transport. From bench to bedside. Diabetes Care 2015; 38:2344-53 |

3. Bailey CJ, Marx N. Cardiovascular protection in type 2 diabetes: insights from recent outcome trials. Diabetes Obes Metab 2018, 21. doi: 10.1111/dom.13492. [Epub ahead of print].

4. Zinman B, Wanner C, Lachin JM et al. Empagliflozin, Cardiovascular Outcomes, and Mortality in Type 2 Diabetes. N Engl J Med 2015; 373:2117-28

5. Wanner C, Inzucchi SE, Lachin JM et al. Empagliflozin and Progression of Kidney Disease in Type 2 Diabetes. N Engl J Med 2016; 375:323-34

6. Neal B, Perkovic V, Mahaffey KW et al. Canagliflozin and Cardiovascular and Renal Events in Type 2 Diabetes. N Engl J Med 2017; 377:644-657

7. Wiviott SD, Raz I, Bonaca MP, Mosenzori O, Kato ET et al. Dapagliflozin and cardiovascular outcomes in type 2 diabetes. N Engl J Med 2018, DOI. 10.1056/NEJMoa1812389

8. Kosiborod M, Cavender MA, Fu AZ et al. Lower risk of heart failure and death in patients Initiated on SGLT-2 inhibitors versus other glucose-lowering drugs: The CVD-REAL study. Circulation 2018, 138: $249-59$

9. Nadkarni GN, Ferrandino R, Chang A et al. Acute kidney injury in patients on SGLT2 inhibitors: a propensity-matched analysis. Diabetes Care 2017, 40, 1479-85.

10. Sattar N, McLaren J, Kristensen SL, Preiss D, McMurray JJ. SGLT2 Inhibition and cardiovascular events: why did EMPA-REG Outcomes surprise and what were the likely mechanisms? Diabetologia 2016; 59:1333-1339.

11. Marx N, McGuire DK. Sodium-glucose cotransporter-2 inhibition for the reduction of cardiovascular events in high-risk patients with diabetes mellitus. Eur Heart J 2016; 37: 3192-3200.

This article is protected by copyright. All rights reserved. 
12. Verma S, McMurray JJ, Cherney DZ. The Metabolodiuretic promise of sodium-dependent glucose cotransporter 2 inhibition: the search for the sweet spot in heart failure. JAMA Cardiology 2017; 2: 939-940.

13. Ferrannini E, Muscelli E, Frascerra $\mathrm{S}$ et al. Metabolic response to sodium-glucose cotransporter 2 inhibition in type 2 diabetic patients. J Clin Invest 2014; 124: 499-508.

14. Striepe K, Jumar A, Ott C et al. Effects of the selective sodium-glucose cotransporter 2 inhibitor empagliflozin on vascular function and central hemodynamics in patients with type 2 diabetes mellitus. Circulation 2017;136:1167-1169.

15. Heerspink HJ, Perkins BA, Fitchett DH, Husain M, Cherney DZ. Sodium glucose cotransporter 2 inhibitors in the treatment of diabetes mellitus: cardiovascular and kidney effects, potential mechanisms, and clinical applications. Circulation 2016;134:752-72.

16. Heerspink HJL, Kosiborod M, Inzucchi SE, Cherney DZI. Renoprotective effects of sodium-glucose cotransporter-2 inhibitors. Kidney Int 2018; 94: 26-39.

17. Rosenstock J, Ferrannini E. Euglycemic diabetic ketoacidosis: a predictable, detectable, and preventable safety concern with SGLT2 inhibitors. Diabetes Care 2015; 38: 1638-42.

18. Kappel BA, Lehrke $M$, Schutt $K$ et al. Effect of empagliflozin on the metabolic signature of patients with type 2 diabetes mellitus and cardiovascular disease. Circulation 2017; 136: 969-72.

19. Li T, Zhang Z, Kolwicz SC, Abell L, et al. Defective branched-chain amino acid catabolism disrupts glucose metabolism and sensitizes the heart to ischemia-reperfusion injury. Cell Metabolism 2017, $25,374-385$

20. Sun H, Olson KC, Gao C et al. Catabolic Defect of Branched-Chain Amino Acids Promotes Heart Failure. Circulation 2016; 133: 2038-49.

21. Bertero E, Prates Roma L, Ameri P, Maack C. Cardiac effects of SGLT2 inhibitors: the sodium hypothesis. Cardiovasc Res 2018; 114: 12-18.

22. Solini A, Sebastiani G, Nigi L, Santini E, Rossi C, Dotta F. Dapagliflozin modulates glucagon secretion in an SGLT2-independent manner in murine alpha cells. Diabetes Metab 2017; 43: 512520.

23. Maiuolo J, Oppedisano F, Gratteri S, Muscoli C, Mollace V. Regulation of uric acid metabolism and excretion. Int J Cardiol 2016, 213, 8-14

24. Mandal AK, Mount DB. The molecular physiology of uric acid homeostasis. Ann Rev Physiol 2016, 77: 323-345.

25. Reaven GM. The kidney: an unwilling accomplice in syndrome X. Am J Kidney Dis 1997; 30: 928-31.

26. Kanbay $M$, Jensen $T$, Solak $Y$ et al. Uric acid in metabolic syndrome: From an innocent bystander to a central player. Eur J Intern Med 2016; 29: 3-8.

27. Yuan $\mathrm{H}, \mathrm{Yu} \mathrm{C}$, Li X et al. Serum uric acid levels and risk of metabolic syndrome: a dose-response meta-analysis of prospective studies. J Clin Endocrinol Metab 2015, 100, 4198-4207.

This article is protected by copyright. All rights reserved. 
28. Zoppini G, Targher G, Chonchol M, Ortalda V, Abaterusso C, Pichiri I, Negri C, Bonora E. Serum uric acid levels and incident chronic kidney disease in patients with type 2 diabetes and preserved kidney function. Diabetes Care 2012; 35: 99-104.

29. Tsai CW, Lin SY, Kuo CC, Huang CC. Serum Uric Acid and Progression of Kidney Disease: A Longitudinal Analysis and Mini-Review. PLoS One. 2017; 12(1): e0170393

30. Kim IY, Lee DW, Lee SB, Kwak. The Role of Uric Acid in Kidney Fibrosis: Experimental Evidences for the Causal Relationship BioMed Res Int 2014, 638732, doi.org/10.1155/2014/638732

31. Yoo TW, Sung KC, Shin HS et al. Relationship Between Serum Uric Acid Concentration and Insulin Resistance and Metabolic Syndrome. Circ J 2005, 69: 928 - 933

32. Zhu Y, Hu Y, Huang $T$ et al. High uric acid directly inhibits insulin signalling and induces insulin resistance. Biochem Biophys Res Comm 2014; 447: 707-14.

33. Kodama S, Saito K, Yachi Y, Asumi M et al. Association Between Serum Uric Acid and Development of Type 2 Diabetes. Diabetes Care 2009; 32: 1737-1742.

34. Bhole V, Choi JW, Kim SW, de Vera M, Choi H. Serum Uric Acid Levels and the Risk of Type 2 Diabetes: A Prospective Study. Am J Med. 2010 ; 123: 957-961.

35. Lv Q, Meng XF, He FF, Chen S, Su H et al. High serum uric acid and increased risk of type 2 diabetes: a systemic review and meta-analysis of prospective cohort studies. PLoS One 2013; 8 , e56864. doi: 10.1371/journal.pone.0056864.

36. Wijnands JM, van Durme CM, Driessen JH, Boonen A et al. Individuals With Type 2 Diabetes Mellitus Are at an Increased Risk of Gout But This Is Not Due to Diabetes. A Population-Based Cohort Study. Medicine 2015; 94: e1358.

37. Zhao Y, Xu L, Tian D, Xia Pet al. Effects of sodium-glucose co-transporter 2 (SGLT2) inhibitors on serum uric acid level: A meta-analysis of randomized controlled trials. Diabetes Obes Metab 2018; 20:458-462.

38. Chino Y, Samukawa Y, Sakai S, Nakai Y, Yamaguchi JI, Nakanishi T,Tamai I. SGLT2 inhibitor lowers serum uric acid through alteration of uric acid transport activity in renal tubule by increased glycosuria. Biopharm Drug Dis 35: 391-404, 2014.

39. Lytvyn Y, Škrtić M, Yang GK Yip PM, Perkins BA, Cherney DZ. Glycosuria-mediated urinary uric acid excretion in patients with uncomplicated type 1 diabetes mellitus. Am J Physiol Renal Physiol 2015; 308: F77-83.

40. So A, Thorens B. Uric acid transport and disease. J Clin Invest. 2010; 120: 1791-1799.

41. Augustin R, Carayannopoulos MO, Dowd LO, Phay JE, Moley JF, Moley KH. Identification and characterization of human glucose transporter-like protein-9 (GLUT9): alternative splicing alters trafficking. J Biol Chem 279: 16229-16236, 2004.

42. Eraly SA, Vallon V, Rieg T, Gangoiti JA et al. Multiple organic anion transporters contribute to net renal excretion of uric acid. Physiol Genomics 2008; 33: 180-192.

43. Bobulescu IA, Moe OW. Renal Transport of Uric Acid: Evolving Concepts and Uncertainties. Adv Chronic Kidney Dis 2012; 19: 358-371.

This article is protected by copyright. All rights reserved. 
44. Maiuolo J, Oppedisano F, Gratteri S, Muscoli C, Mollace V. Regulation of uric acid metabolism and excretion. Int j Cardiol 2016; 213: 8-14.

45. Tan PK, Ostertag TM, Miner JN. Mechanism of high affinity inhibition of the human urate transporter URAT1. Scientific Reports 2016, 6, 34995.

46. Ichida K, Hosoyamada M, Kamatani N, Kamitsuji S, Hisatome I, Shibasaki T, Hosoya T. Age and origin of the G774A mutation in SLC22A12 causing renal hypouricemia in Japanese. Clin Genet 2008; 74: 243-51.

47. Perlstein TS, Gumieniak O, Williams GH, Sparrow D et al. Uric Acid and the Development of Hypertension. Hypertension. 2006; 48:1031-1036

48. Grayson PC, Kim SY, LaValley M, Choi HK. Hyperuricemia and Incident Hypertension: A Systematic Review and Meta-Analysis. Arthritis Care Res (Hoboken). 2011; 63: 102-110.

49. Wang J, Qin T, Chen J, Li Y, Wang L, Huang H, et al. (2014) Hyperuricemia and Risk of Incident Hypertension: A Systematic Review and Meta-Analysis of Observational Studies. PLoS ONE 2014; 9 : e114259.

50. Caglı K, Turak O, Canpolat U, Ozcan F et al. Association of Serum Uric Acid Level with Blood Pressure Variability in Newly Diagnosed Essential Hypertension. J Clin Hypertension 2015; 17: 929935.

51. Feig D, Soletsky B, Johnson RJ. Effect of allopurinol on blood pressure of adolescents with newly diagnosed essential hypertension: a randomized trial. JAMA 2008; 300: 924-932.

52. Gunawardhana L, McLean L, Punzi HA, Hunt B et al. Effect of Febuxostat on Ambulatory Blood Pressure in Subjects with Hyperuricemia and Hypertension: A Phase 2 randomized PlaceboControlled Study. Am Heart Assoc 2017; 6: e006683. DOI: 10.1161/JAHA.117.006683.

53. Agarwal V, Hans N, Messerli FH. Effect of Allopurinol on Blood Pressure: A Systematic Review and Meta-Analysis. J Clin Hypertension 2013, 15: 435-42.

54. Beattie CL, Fulton RL, Higgins P, Padmanabhan S et al. Allopurinol Initiation and Change in Blood Pressure in Older Adults with Hypertension. Hypertension 2014; 64: 1102-1107.

55. Qu LH, Jiang $\mathrm{H}$, Chen JH. Effect of uric acid-lowering therapy on blood pressure: systematic review and meta-analysis. Ann Med 2017; 49:142-156.

56. Zoccali C, Maio R, Mallamaci F, Sesti G, Perticone F. Uric acid and endothelial dysfunction in essential hypertension. J Am Soc Nephrol 2006; 17: 1466-71.

57. Tsai WC1, Huang YY, Lin CC, Li WT, Lee CH, Chen JY, Chen JH. Uric acid is an independent predictor of arterial stiffness in hypertensive patients Heart Vessels. 2009; 24: 371-5.

58. Mehta T, Nuccio E, McFann K, Madero M, Sarnak MJ, Jalal D. Association of Uric Acid With Vascular Stiffness in the Framingham Heart Study. Am J Hypertens. 2015; 28: 877-883.

59. Chaudhary K, Malhotra K, Sowers J, Aroor A. Uric Acid - Key Ingredient in the Recipe for Cardiorenal Metabolic Syndrome Cardiorenal Med 2013; 3: 208-220.

60. Saito I, Saruta T, Kondo K, Nakamura R et al. Serum Uric Acid and the Renin-Angiotensin System in Hypertension. J Am Ger Soc 1978, 6, 241-247

This article is protected by copyright. All rights reserved. 
61. Aroor AR, DeMarco VG, Jia G, Sun Z et al. The Role of Tissue Renin-Angiotensin-Aldosterone System in the Development of Endothelial Dysfunction and Arterial Stiffness. Front Endocrinol 2013; 4: 161. doi: 10.3389/fendo.2013.00161.

62. Wang Y, Chu C, Wang KK, Hu JW et al. Effect of Salt Intake on Plasma and Urinary Uric Acid Levels in Chinese Adults: An Interventional Trial. Scientific Reports 2018, 8, 1434.

63 Mazzali M, Kanbay M, Segal MS, Shafiu M, Jalal D, Feig DI, Johnson RJ. Uric acid and hypertension: cause or effect? Curr Rheumatol Rep 2010; 12: 108-17.

64. Feig DI, Kang DH, Johnson RJ. Uric acid and cardiovascular disease. N Engl J Med 2008; 359:1811-1821

65. Holme I, Aastveit AH, Hammar N, Jungner I, Walldius G. Uric acid and risk of myocardial infarction, stroke and congestive heart failure in 417,734 men and women in the Apolipoprotein MOrtality RISk study (AMORIS). J Intern Med 2009; 266: 558-70.

66. Huang $\mathrm{H}$, Huang B, Li Y, Huang Y, Li J, Yao H, et al. Uric acid and risk of heart failure: a systematic review and meta-analysis. Eur J Heart Fail 2014; 16:15-24.

67. Shimizu T, Yoshihisa A, Kanno Y, Takiguchi M, Sato A, Miura S, et al. Relationship of hyperuricemia with mortality in heart failure patients with preserved ejection fraction. Am J Physiol Heart Circ Physiol 2015; 309: H1123-9.

68. Kuwabara M. Hyperuricemia, Cardiovascular Disease, and Hypertension. Pulse 2016, 3: 242252.

69. Mantovani A, Rigolon R, Pichiri I, Pernigo M, Bergamini C, Zoppini G, et al. Hyperuricemia is associated with an increased prevalence of atrial fibrillation in hospitalized patients with type 2 diabetes. J Endocrinol Invest 2016; 39: 159-67.

70. Storhaug HM, Norvik JV, Toft I, Eriksen BO et al. Uric acid is a risk factor for ischemic stroke and all-cause mortality in the general population: a gender specific analysis from The Troms $\varnothing$ Study.

BMC Cardiovasc Disord 2013; 13: 115. doi: 10.1186/1471-2261-13-115

71. Clarson LE, Chandratre P, Hider SL, Belcher J, Heneghan C, Roddy E et al. Increased cardiovascular mortality associated with gout: a systematic review and meta-analysis. Eur J Prev Cardiol 2015; 22: 335-43.

72. Braga F, Pasqualetti S, Ferraro S, Panteghini M. Hyperuricemia as risk factor for coronary heart disease incidence and mortality in the general population: a systematic review and meta-analysis. Clin Chem Lab Med 2015. 10.1515/cclm-2015-0523.

73. Li M, Hu X, Fan Y, Li K et al. Hyperuricemia and the risk for coronary heart disease morbidity and mortality a systematic review and dose-response meta-analysis. Sci Rep 2016; 6: 19520. doi: 10.1038/srep19520.

74. Zoppini G, Targher G, Negri C, Stoico V et al. Elevated Serum Uric Acid Concentrations Independently Predict Cardiovascular Mortality in Type 2 Diabetic Patients. Diabetes Care 2009; 32: 1716-1720.

75. Kawai T, Ohishi M, Takeya $Y$, Onishi $M$ et al. Serum uric acid is an independent risk factor for cardiovascular disease and mortality in hypertensive patients Hypertension Research 2012, 35, 1087-1092

This article is protected by copyright. All rights reserved. 
76. Martínez-Quintana E, Tugores A, Rodríguez-González F. Serum uric acid levels and cardiovascular disease: the Gordian knot. J Thorac Dis 2016; 8: E1462-E1466.

77. Chang $\mathrm{CC}, \mathrm{Wu} \mathrm{CH}$, Liu LK, Chou RH et al. Association between serum uric acid and cardiovascular risk in nonhypertensive and nondiabetic individuals: The Taiwan I-Lan Longitudinal Aging Study. Scientific Reports 2018, 8, 5234. doi:10.1038/s41598-018-22997-0

78. Zhao G, Huang L, Song $M$, Song $Y$. Baseline serum uric acid level as a predictor of cardiovascular disease related mortality and all-cause mortality: A meta-analysis of prospective studies. DOI: https://doi.org/10.1016/j.atherosclerosis.2013.08.023

79. Wheeler JG, Juzwishin KD, Eiriksdottir G, Gudnason V, Danesh J. Serum uric acid and coronary heart disease in 9,458 incident cases and 155,084 controls: prospective study and meta-analysis. PLoS Med 2005; 2: e76.

80. George J, Carr E, Davies J, Belch J, Struthers A. High-Dose Allopurinol Improves Endothelial Function by Profoundly Reducing Vascular Oxidative Stress and Not by Lowering Uric Acid. Circulation 2006, 114: 2508-2516.

81. Higgins P, Dawson J, Lees KR, McArthur K, Quinn TJ, Walters MR. Xanthine oxidase inhibition for the treatment of cardiovascular disease: a systematic review and meta-analysis. Cardiovasc Ther 2012;30:217-226.

82. Grimaldi-Bensouda L, Alpérovitch A, Aubrun E, et al; Impact of Allopurinol on Risk of Myocardial Infarction. Ann Rheum Dis 2015; 74: 836-842

83. Maria Lorenza A, Agabiti-Rosei MC, Paini A, Salvetti M. Uric Acid And Cardiovascular Disease: An Update. European Cardiology Review 2016; 11: 54-9

84. Maclsaac RL, Salatski J, Higgins P, Walters MR, et al. Allopurinoil and cardiovascular outcomes in adults with hypertension. Hypertension 2016; 67: 535-540

85. Singh JA, Ramachandaran R, Yu S, Curtis JR. Allopurinol use and the risk of acute cardiovascular events in patients with gout and diabetes. BMC Cardiovascular Disorders 2017 17: 76. https://doi.org/10.1186/s12872-017-0513-6.

86. Larsen KS, Pottegård A, Lindegaard HM, Hallas J. Effect of Allopurinol on Cardiovascular Outcomes in Hyperuricemic Patients: A Cohort Study. Am J Med 2016; 129: 299-306.

87. Thanassoulis G, Brophy JM, Richard H et al. Gout, Allopurinol Use, and Heart Failure Outcomes. Arch Intern Med 2010; 170: 1358-1364.

88. Nakagomi A, Saiki Y, Noma S, Kohashi K et al. Effects of febuxostat and allopurinol on the inflammation and cardiac function in chronic heart failure patients with hyperuricemia IJC Metabolic Endocrine 2015, 8; 46-55.

89. White WB, Saag KG, Becker MA. Cardiovascular Safety of Febuxostat or Allopurinol in Patients With Gout. N Engl J Med 2018; 378: 1200-10.

90. Kim SC, Neogi T, Kang EH, Liu J, Desai RJ, Zhang M, Solomon DH. Cardiovascular Risks of Probenecid Versus Allopurinol in Older Patients With Gout. J Am Coll Cardiol 2008; 71: 994-1004.

91. Sautin YY, Johnson RJ. Uric acid: the oxidant-antioxidant paradox. Nucleosides Nucleotides Nucleic Acids. 2008; 27: 608-619.

This article is protected by copyright. All rights reserved. 
92. Paravicini TM, Touyz RM. NADPH Oxidases, Reactive Oxygen Species, and Hypertension Clinical implications and therapeutic possibilities. Diabetes Care 2008; 31 (Suppl. 2): S170-S180.

93. Sedeek M, Nasrallah R, Touyz RM, Hébert RL. NADPH Oxidases, Reactive Oxygen Species, and the Kidney: Friend and Foe. J Am Soc Nephrol 2013; 24: 1512-1518.

94. Gasse P, Riteau N, Charron S, Girre S et al. Uric Acid Is a Danger Signal Activating NALP3 Inflammasome in Lung Injury Inflammation and Fibrosis. Am J Respir Crit Care Med 2009, 179, 903913.

95. Kang DH, Park SK, Lee IK, Johnson RJ. Uric acid-induced C-reactive protein expression: implication on cell proliferation and nitric oxide production of human vascular cells. J Am Soc Nephrol 2005, 16: 3553-3562.

96. Verzola D, Ratto E, Villaggio B, Parodi EL, Pontremoli R, Garibotto G et al. Uric Acid Promotes Apoptosis in Human Proximal Tubule Cells by Oxidative Stress and the Activation of NADPH Oxidase NOX 4. PLOS ONE 2014, 9: e115210.

97. Corry DB, Eslami P, Yamamoto K, Nyby MD, Makino H, et al. Uric acid stimulates vascular smooth muscle cell proliferation and oxidative stress via the vascular renin-angiotensin system. J Hypertension 2008, 26: 269-275.

98. Kırça M, Oguz N, Çetin A, Uzuner F, Yesilkaya A. Uric acid stimulates proliferative pathways in vascular smooth muscle cells through the activation of p38 MAPK, p44/42 MAPK and PDGFRb. J Recept Signal Transduct Res 2016; 12: 1-7.

99. Prattichizzo F, De Nigris V, Micheloni S, La Sala L, Ceriello A. Increases in circulating levels of ketone bodies and cardiovascular protection with SGLT2 inhibitors: Is low-grade inflammation the neglected component? Diabetes Obesity Metabolism 2018, 21. doi.org/10.1111/dom.13488

100. Yu MA, Sánchez-Lozada LG, Johnson RJ, Kang DH. Oxidative stress with an activation of the renin-angiotensin system in human vascular endothelial cells as a novel mechanism of uric acidinduced endothelial dysfunction. J Hypertension 2010; 28: 1234-42.

101. Gersch C, Palii SP, Kim KM, Angerhofer A, Johnson RJ, Henderson GN. Inactivation of nitric oxide by uric acid. Nucleosides Nucleotides Nucleic Acids. 2008; 27: 967-978.

102. Li P, Zhang L, Zhang M, Zhou C, Lin N. Uric acid enhances PKC-dependent eNOS phosphorylation and mediates cellular ER stress: a mechanism for uric acid-induced endothelial dysfunction. Int J Mol Med 2016; 37: 989-97.

103. Zoppini G, Targher G, Chonchol M et al. Serum uric acid levels and incident chronic kidney disease in patients with type 2 diabetes and preserved kidney function. Diabetes Care 2012; 35: 99104.

104. De Cosmo S, Viazzi F, Pacilli A, Giorda C et al. Serum Uric Acid and Risk of CKD in Type 2 Diabetes. Clin J Am Soc Nephrol 2015; 10: 1921-1929.

105. Chang YH, Lei CC, Lin KC, Chang DM, Hsieh CH, Lee YJ. Serum uric acid level as an indicator for CKD regression and progression in patients with type 2 diabetes mellitus-a 4.6-year cohort study. Diabetes Metab Res Revs 2016, 32, 557-564.

This article is protected by copyright. All rights reserved. 
106. Gu L, Huang L, Wu H, Lou Q, Bian R. Serum uric acid to creatinine ratio: A predictor of incident chronic kidney disease in type 2 diabetes mellitus patients with preserved kidney function. Diab Vasc Dis Res 2017; 14: 221-225.

107. Altemtam N, Russell J, El Nahas M. A study of the natural history of diabetic kidney disease (DKD). Nephrol Dial Transplant 2012; 27: 1847-1854.

108. Hovind $P$, Rossing $P$, Tarnow L, JohnsonRJ, Parving HH. Serum uric acid as a predictor for development of diabetic nephropathy in type 1 diabetes: an inception cohort study. Diabetes 2009; 58: 1668-1671.

109. Ficociello LH, Rosolowsky ET, Niewczas MA, et al. High-normal serum uric acid increases risk of early progressive renalfunction loss in type 1 diabetes: results of a 6-year follow-up. Diabetes Care 2010; 33: 1337-1343.

110. Johnson RJ, Nakagawa T, Jalal D, Sánchez-Lozada LG, Kang DH, Ritz E. Uric acid and chronic kidney disease: which is chasing which? Nephrol Dial Transplant 2013; 28: 2221-2228.

111. Xia X, Luo Q, Li B, Lin Z, Yu X, Huang F. Serum uric acid and mortality in chronic kidney disease: A systematic review and meta-analysis. Metabolism 2016; 65: 1326-41.

112. Miao Y, Ottenbros SA, Laverman GD, et al. Effect of a reduction in uric acid on renal outcomes during losartan treatment: a post hoc analysis of the reduction of endpoints in non-insulindependent diabetes mellitus with the Angiotensin II Antagonist Losartan Trial. Hypertension 2011; 58: $2-7$.

113. Goicoechea M, Garcia de Vinuesa S, Verdalles U. et al. Allopurinol and progression of CKD and cardiovascular events: long-term follow-up of a randomized clinical trial. Am J Kidney Dis. 2015; 65: 543-549

114. Kosugi $T$, Nakayama $T$, Heinig $M$, et al. Effect of lowering uric acid on renal disease in the type 2 diabetic db/db mice. Am J Physiol Renal Physiol 2009; 297: F481-F488.

115. Johnson RJ, Segal MS, Srinivas T, et al. Essential hypertension, progressive renal disease, and uric acid: a pathogenetic link?. J Am Soc Nephrol 2005, 16: 1909-19.

116. DiBianco JM, Jarrett TW, Mufarrij P. Metabolic syndrome and nephrolithiasis risk: should the medical management of nephrolithiasis include the treatment of metabolic syndrome? Rev Urol 2015; 17: 117-28.

117. Mazzali M, Kanellis J, Han L, Feng I, et al. Hyperuricemia induces a primary renal arteriolopathy in rats by a blood pressure-independent mechanism Am J Physiol Renal Physiol 2002, 282: F991-F997.

118. Sanchez-Lozada LG, Tapia E, Santamaria J, et al. Mild hyperuricemia induces vasoconstriction and maintains glomerular hypertension in normal and remnant kidney rats. Kidney Int 2005; 67: 237-247

119. Kim IY, Lee DW, Lee SB, Kwak IS. The Role of Uric Acid in Kidney Fibrosis: Experimental Evidences for the Causal Relationship BioMed Research 2014, 638732.

120. Ohashi N, Ishigaki S, Isobe $\mathrm{S}$, Tsuji $\mathrm{N}$, et al. Hyperuricaemia is associated with renal damage independently of hypertension and intrarenal renin-angiotensin system activation, as well as their circadian rhythms. Nephrology 2015; 20: 814-9.

This article is protected by copyright. All rights reserved. 
121. Ryu E-S, Kim MJ, Shin H-S, et al. Uric acid-induced phenotypic transition of renal tubular cells as a novel mechanism of chronic kidney disease. Am J Physiol 2013; 304: F471-80.

122. Zhou $Y$, Fang $L$, Jiang $L$ et al. Uric acid induces renal inflammation via activating tubular NFkappaB signaling pathway. PLoS ONE 2012; 7: e39738

123. Li S1, Zhao F, Cheng S, Wang X, Hao Y. Uric acid-induced endoplasmic reticulum stress triggers phenotypic change in rat glomerular mesangial cells. Nephrology 2013; 18: 682-9.

124. Delbarre F, Amor B, Auscher C, De Gery A. Treatment of gout with allopurinol. Ann Rheum Dis 1966, 25, 62733.

125. Borghi G, Pere F. Urate lowering therapies in the treatment of gout: a systematic review and meta-analysis. Eur Rev Med Pharmacol Sci 2016, 20, 983-93

126. Castro VMF, Melo AC, Belo VS, Chaves VE. Effect of allopurinol and uric acid normalization on serum lipids hyperuricemic subjects: A systematic review with meta-analysis. Clin Biochem 2017 ; 50: 1289-1297.

127. Fan M, Liu J, Zhao B, X. Wu X, Gu J. AB0819 Indirect Comparison of Urate-Lowering Therapies for Hyperuricemic Patients with or without Gout: Meta-Analysis of Randomized Controlled Trials. Ann Rheumatic Dis 2016, 75, ABO819.

128. A Study to Assess the Effect of Intensive Uric Acid (UA) Lowering Therapy With RDEA3170, Febuxostat, Dapagliflozin on Urinary Excretion of UA. Clinical trial NCT0331613. https://clinicaltrials.gov/ct2/show/NCT0331613 accessed 2 August 2018.

129. Zhang S, Wang Y, Liu W et al. 3-Oxodapagliflozin as a Potent and Highly Selective SGLT2 Inhibitor for the Treatment of Type 2 Diabetes. Chem Res Chinese Univs 2014; 30:785-793. DOI: 10.1007/s40242-014-4043-9

130. Davies MJ, Trujillo A, Vijapurkar U, Damaraju CV, Meininger G. Effect of canagliflozin on serum uric acid in patients with type 2 diabetes mellitus. Diabetes Obes Metab, 2015, 17, 426-9.

131. Kutoh E, Hori T. Effect of Pioglitazone on Serum Uric Acid Levels in Newly Diagnosed, DrugNaïve Patients with Type 2 Diabetes Endocr Res. 2012, 38, 151-9.

132. Niu SW, Chang KT, Lin HY, Kuo IC, Chang YH, Chen YH, Hung CC, Chiu YW, Hwang SJ.

Decreased incidence of gout in diabetic patients using pioglitazone. Rheumatology 2018, 57:92-99.

133. Tonneijck L, Muskiet MHA, Smits MM, Bjornstad P, Kramer MHH, Diamant M, Hoorn EJ, Joles J, van Raalte DH. Effect of immediate and prolonged GLP-1 receptor agonist administration on uric acid and kidney clearance: Post-hoc analyses of four clinical trials. Diabetes Obes Metab 2018, 20:1235-1245.

This article is protected by copyright. All rights reserved. 


\section{Figures below}

\section{Legend to Figure}

\section{Figure 1.}

SGLT2 inhibitors Increase renal urate elimination. This involves filtration of urate, most of which is reabsorbed in segment $\mathrm{S} 1$ of the proximal tubule, while urate is also secreted into the nephron lumen mostly in segment S2 and more distally. SGLT2 inhibitors increase the concentration of glucose in the proximal tubules, and current evidence indicates that the glucose competes with urate for the facilitative hexose/urate transporter GLUT9b, reducing urate reabsorption.

ABCG2, ATP-binding cassette transporter G2; GLUT9a/b, glucose transporter SLC2A9 isoform a or b; MRP-4, multidrug resistance-associated protein-4; NPT, sodium/phosphate co-transporter; OAT, organic anion transporter; SGLT, sodium/glucose co-transporter; URAT1, urate transporter SLC22A12.

\section{Figure 2.}

SGLT2 inhibitors increase urate elimination in the urine which reduces plasma urate concentration. Lower plasma urate concentrations contribute to the cardiovascular and renal protective effects of SGLT2 inhibitors.

GLUT, glucose transporter; NADPH, nicotinamide adenine dinucleotide phosphate; PCT, proximal convoluted tubule; S1, S2, segments 1 and 2 of proximal convoluted tubule; SGLT, sodium/glucose co-transporter.

This article is protected by copyright. All rights reserved. 


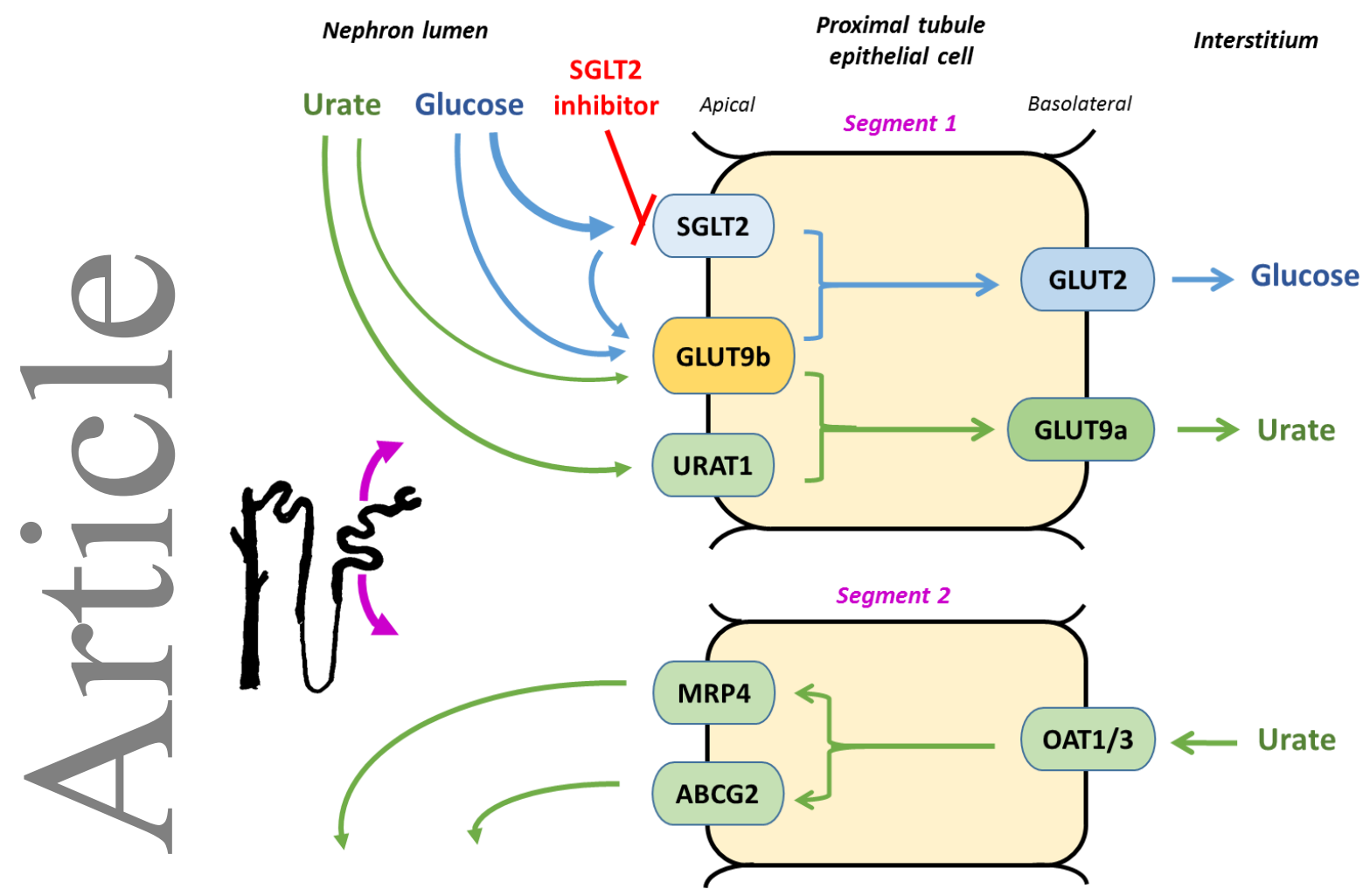

Bailey. Figure 1.
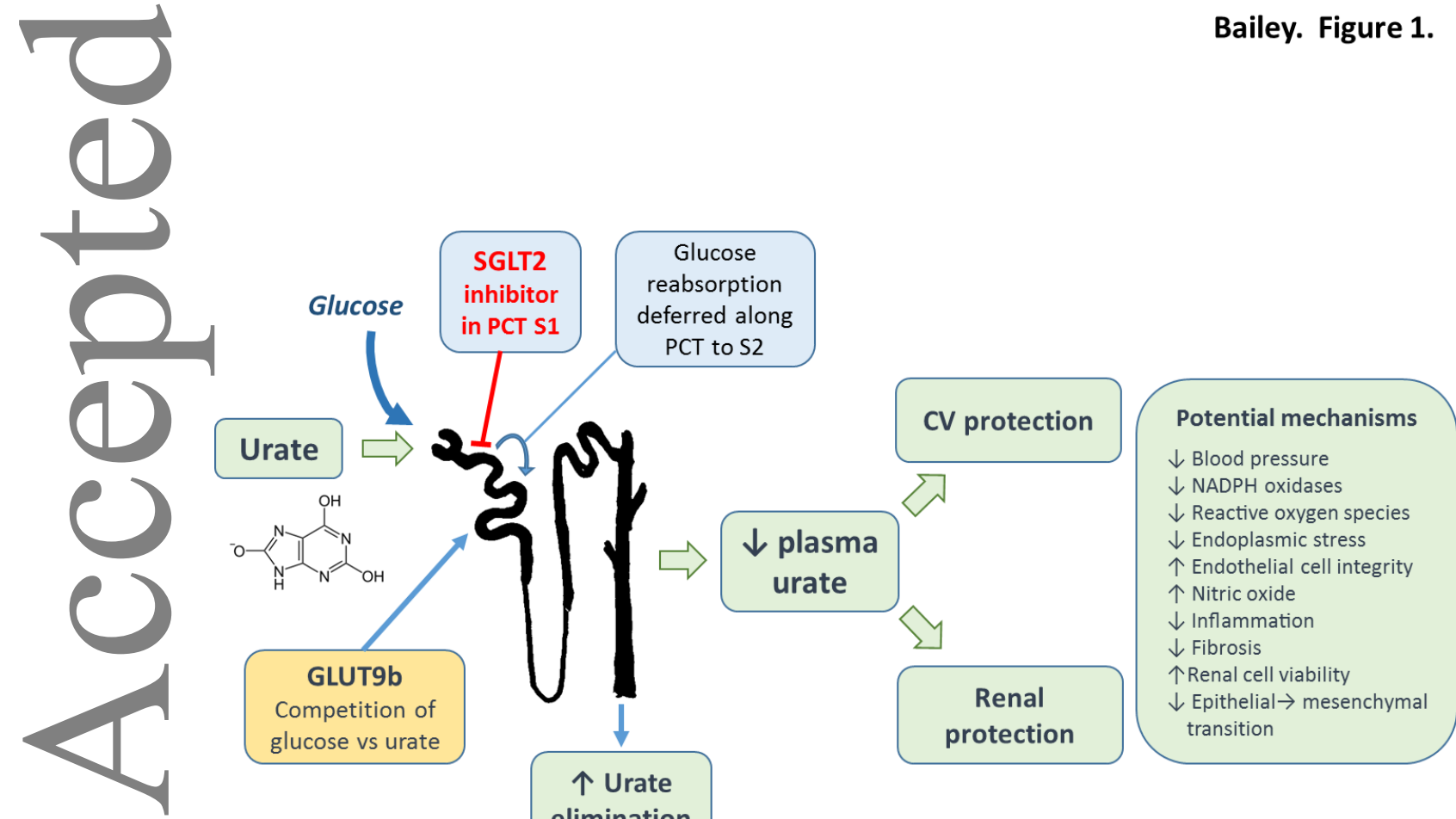

Bailey. Figure 2.

This article is protected by copyright. All rights reserved. 